\title{
Pro-neurogenic effect of fluoxetine in the olfactory bulb is concomitant to improvements in social memory and depressive-like behavior of socially isolated mice
}

\author{
Leonardo O. Guarnieri ${ }^{1,2}$, Ana Raquel Pereira-Caixeta'1, Daniel C. Medeiros'ㄹ, Nayara S. S. Aquino ${ }^{3}$, Raphael E. Szawka ${ }^{3}$, \\ Eduardo M. A. M. Mendes $\mathbb{1}^{2}$, Márcio F. D. Moraes ${ }^{1,2}$ and Grace S. Pereira (1)
}

\begin{abstract}
Although loneliness is a human experience, it can be estimated in laboratory animals deprived from physical contact with conspecifics. Rodents under social isolation (SI) tend to develop emotional distress and cognitive impairment. However, it is still to be determined whether those conditions present a common neural mechanism. Here, we conducted a series of behavioral, morphological, and neurochemical analyses in adult mice that underwent to 1 week of SI. We observed that SI mice display a depressive-like state that can be prevented by enriched environment, and the antidepressants fluoxetine (FLX) and desipramine (DES). Interestingly, chronic administration of FLX, but not DES, was able to counteract the deleterious effect of SI on social memory. We also analyzed cell proliferation, neurogenesis, and astrogenesis after the treatment with antidepressants. Our results showed that the olfactory bulb (OB) was the neurogenic niche with the highest increase in neurogenesis after the treatment with FLX. Considering that after FLX treatment social memory was rescued and depressive-like behavior decreased, we propose neurogenesis in the OB as a possible mechanism to unify the FLX ability to counteract the deleterious effect of SI.
\end{abstract}

\section{Introduction}

Even though humans are naturally social animals, choosing to be alone can provide a positive state of satisfaction. Conversely, loneliness, characterized by being a non-temporary condition, is a subjective state with negative impacts on physical and mental health ${ }^{1-3}$. In fact, the consistent unpleasant experience of being alone can even predict depressive symptomatology ${ }^{4-7}$.

Depression is a mood disorder with heterogeneous symptoms and etiology (American Psychiatric Association, 1994). Despite the behavioral symptoms ${ }^{6-8}$, appetite

\footnotetext{
Correspondence: Grace S. Pereira (grace@icb.ufmg.br)

${ }^{1}$ Núcleo de Neurociências, Universidade Federal de Minas Gerais, Belo Horizonte, Brazil

${ }^{2}$ Centro de Tecnologia e Pesquisa em Magneto Ressonância, Programa de PósGraduação em Engenharia Elétrica, Universidade Federal de Minas Gerais, Belo Horizonte, Brazil
}

Full list of author information is available at the end of the article. and weight changes are common, though inconstant physiological markers for depression ${ }^{8}$. Anatomically, hippocampus and olfactory bulb $(\mathrm{OB})$ are reduced in some cases of depression ${ }^{9}$. Furthermore, depression is usually associated with disruption of episodic memory $^{10,11}$, such as impaired recollection, exacerbated memory for negative content ${ }^{12}$, and the weakening of positive memories ${ }^{13,14}$. Nevertheless, the mechanisms of memory disruption in depression are still poorly understood $^{15}$.

The pharmacological treatment for depression includes fluoxetine, a selective serotonin (5-HT) reuptake inhibitor, and desipramine, a tricyclic antidepressant which inhibits the reuptake of norepinephrine (NE), but also 5$\mathrm{HT}^{16,17}$. Lower concentrations of $\mathrm{NE}$ and $5-\mathrm{HT}$ in the brain ${ }^{18-20}$ along with the effectiveness of antidepressant

\section{(c) The Author(s) 2020}

(c) (i) Open Access This article is licensed under a Creative Commons Attribution 4.0 International License, which permits use, sharing, adaptation, distribution and reproduction cc. in any medium or format, as long as you give appropriate credit to the original author(s) and the source, provide a link to the Creative Commons license, and indicate if changes were made. The images or other third party material in this article are included in the article's Creative Commons license, unless indicated otherwise in a credit line to the material. If material is not included in the article's Creative Commons license and your intended use is not permitted by statutory regulation or exceeds the permitted use, you will need to obtain permission directly from the copyright holder. To view a copy of this license, visit http://creativecommons.org/licenses/by/4.0/. 
drugs $^{21,22}$ support the monoaminergic hypothesis of depression.

Alternatively, neurogenesis has arisen as a pivotal mechanism in the pathogenesis of depression ${ }^{23}$. Unmedicated depressed adults presented less granule neurons in the anterior dentate gyrus (DG) when compared to healthy controls ${ }^{24}$, which agrees with reduced hippocampal volume findings observed in patients with major depression $^{25}$. Accordingly, neurogenesis has been proposed by several independent researchers as one of the mechanisms for the antidepressant effect of fluoxetine $\mathrm{e}^{26,27}$.

Evidence suggest that loneliness is not a solely human experience ${ }^{28}$. Objective loneliness can be induced in laboratory animals by depriving them from physical contact with conspecifics. Rearing mice on social isolation (SI) may induce depressive, anxious and aggressive behaviors later on life $\mathrm{e}^{29,30}$ and it is usually used as an animal model for stress ${ }^{31,32}$. SI during adulthood, however, is less studied, although their behavioral effects has been shown to depend on SI duration ${ }^{33}$.

One emerging field that has been the focus of our research is to understand the effects of SI on a specific type of episodic memory named social recognition memory ${ }^{23,34}$. One week of SI is deleterious for the longterm maintenance of social memory in mice ${ }^{35-37}$, although did not affect other hippocampus-dependent memories ${ }^{36}$. Interestingly, enriched environment blunted the effect of SI on memory ${ }^{36}$ in a neurogenesis-dependent manner ${ }^{38}$. In fact, the formation of social recognition memory seems reliant on neurogenesis ${ }^{39,40}$.

Here we raised the hypothesis that $\mathrm{SI}$ is a condition that induces episodic memory impairment and depressive-like behaviors, allowing to investigate the mechanisms of memory disruption in depression. This work examines the behavioral, pharmacological, morphological, and neurochemical features of depression in isolated mice. We also tested the antidepressant potential of fluoxetine, desipramine, and the enriched environment in the SI model. Our study proposes neurogenesis as a core mechanism involved in the antidepressant and promnesic effects of fluoxetine and enriched environment.

\section{Material and methods Subjects}

We used 164 adults (8-12 weeks of age) (30 females and 134 males) and 36 juveniles (21-35 days of age, only used as a social stimulus) Swiss mice. All animals were maintained in a climate-controlled environment $\left(22 \pm 2{ }^{\circ} \mathrm{C}\right.$, humidity at $55 \pm 10 \%$ ) under a $12 \mathrm{~h}$ light/dark cycle. All behavioral experiments were performed during the light phase. Both food and water were available ad libitum. The animals were randomly placed in one of the following groups: group housed in standard environment
(CONTROL); group housed in enriched environment (CONTROL + ENRICHMENT); individually housed in standard environment (SOCIAL ISOLATION), and individually housed in enriched environment (SOCIAL ISOLATION + ENRICHMENT). Animals were maintained in polypropylene cages $(28 \mathrm{~cm} \times 17 \mathrm{~cm} \times 12 \mathrm{~cm})$, except the control + enrichment group that was maintained in bigger polypropylene cage $(40 \mathrm{~cm} \times 33 \mathrm{~cm} \times$ $16 \mathrm{~cm}$ ). The enriched environment was provided by the addition of ribbons, pieces of plastic, cardboard rolls and toys into the cage. Animals were maintained in each condition during at least 7 days.

All experiments were performed in compliance with the guidelines from the National Council for Animal Experimentation Control (CONCEA-BRAZIL). All protocols were approved by the Institutional Ethics Committee on the Use of Animals at the Universidade Federal de Minas Gerais (CEUA/UFMG) (no. 177/2014).

The investigator was blinded to the group allocation during the experiment and during assessing the outcoming results.

\section{Metabolic evaluation}

Animals were weighted daily during 7 days. During the same period, the consumption of food and water was measured. All these measurements were taken at 9:00 a.m.

\section{Behavioral analysis \\ Forced-swimming test}

Animals were placed individually in a glass cylinder ( $35 \mathrm{~cm}$ high, $24 \mathrm{~cm}$ in diameter) filled with water $\left(28^{\circ} \mathrm{C}\right.$ ) to the height of $14 \mathrm{~cm}$. During $6 \mathrm{~min}$, time of immobility was quantified $^{41,42}$.

\section{Tail suspension test}

Mice were suspended by the tail and attached to a metal rod $(50 \mathrm{~cm}$ height) for a period of $6 \mathrm{~min}$. After $1 \mathrm{~min}$ habituation, total immobility time was scored. Immobility was considered as the absence of movements in the hindlimbs and forelimbs ${ }^{43,44}$.

\section{Sucrose preference test}

Animals were individually placed in cages containing two bottles, one filled with water and the other one with $3 \%$ sucrose solution. During the first $3 \mathrm{~h}$, the bottles were weighed every $1 \mathrm{~h}$. After, bottles were weighed 12, 24, and $48 \mathrm{~h}$. Between each measure we changed the position of the bottle to avoid spatial cues. The preference for sucrose over water was calculated by the following formula: [sucrose consumed/(sucrose + water consumed)]. Results were expressed as the percentage of sucrose preference $^{45}$. 


\section{Social recognition}

Habituation phase consisted in introducing the adult mouse inside a clean cage $(28 \mathrm{~cm} \times 17 \mathrm{~cm} \times 12 \mathrm{~cm})$ containing an empty cylinder, with 60 evenly spaced holes on its walls, for a period of $30 \mathrm{~min}$. During the last $5 \mathrm{~min}$, a juvenile mouse was introduced into an identical cylinder, within its own cage. Training session (TR) lasted 5 min and consisted in replacing the empty cylinder by the one containing the juvenile mouse. Social exploration was scored every time the adult's nose or whiskers were introduced in the cylinder's holes. Test session (TT) was identical to TR, lasted $5 \mathrm{~min}$ and was performed either $1.5 \mathrm{~h}$ later, in case of testing short-term memory (STM) or $24 \mathrm{~h}$ after TR to test long-term memory (LTM). Results were expressed as social recognition index [time exploring the juvenile during TT/ time exploring the juvenile during $\mathrm{TR}+\mathrm{TT}]^{40}$.

\section{Open field}

An automated system (Actitrack v2.7.13.) was used to evaluate the locomotor activity in the open field. The apparatus consists of an acrylic arena $(25 \times 25 \mathrm{~cm})$, coupled to two external infrared systems that monitor the total distance traveled by the animal during $5 \mathrm{~min}$. The arena was cleaned with $70 \%$ alcohol after each animal ${ }^{46}$.

\section{Pharmacological treatment}

Fluoxetine hydrochloride [(Sigma, St. Louis, MO) 30 and $45 \mathrm{mg} / \mathrm{kg}$ ] and desipramine hydrochloride [Sigma, St. Louis, MO) 30 and $45 \mathrm{mg} / \mathrm{kg}$ ] were diluted in saline and were administered intraperitoneally $20 \mathrm{~min}$ before the respective test (acute treatment) or daily during 7 days (chronic treatment).

\section{Magnetic resonance imaging}

Animals were maintained anesthetized with isoflurane (3\% induction and $1.5 \%$ maintenance) while inside the 4.7 T NMR system (Oxford). Imaging protocol consisted on the acquisition of T2-weighted coronal images (TR = $3000 \mathrm{~ms}, \mathrm{TE}=50 \mathrm{~ms}$ ) with a total of 20 contiguous slices of $1 \mathrm{~mm}$ thickness $(512 \times 256 \text { voxels })^{40}$.

Images were evaluated using masks for the $\mathrm{OB}$ and the hippocampus, constructed manually, using a tablet driver (Bamboo Tablet Driver, V5.2.5 WIN; WACOM Technology Corporation, USA) and MeVisLab software (MeVis Medical Solutions AG, Fraunhofer). Volumetric quantification was done using MatLab ${ }^{\circledR}$ scripts $^{47}$.

\section{Quantification of serotonin (5-HT) and NE by high- performance liquid chromatography}

$\mathrm{OB}$, dorsal, and ventral hippocampus were homogenized in 450,150 , and $200 \mu \mathrm{L}$, respectively, of a solution containing $0.15 \mathrm{M}$ perchloric acid, 0.1 mM EDTA, and 3,4dihydroxybenzylamine (DHBA; Aldrich, Milwaukee, WI) as the internal standard. The homogenate was centrifuged for $20 \mathrm{~min}$ at $12,000 \mathrm{~g}$. Protein content was determined from the pellet by the Bradford method ${ }^{48}$. In the supernatant, concentrations of NE and serotonin $(5-\mathrm{HT})$ were determined by high-performance liquid chromatography (HPLC) with electrochemical detection. Briefly, chromatographic separation was performed with a C18 column (Purospher Star, $5 \mu \mathrm{m}, 250 \times 4 \mathrm{~mm}$; Merck Darmstadt, Germany), preceded by pre-column C18 (Lichrospher, $5 \mu \mathrm{m}, 4 \times 4 \mathrm{~mm}$; Merck). The mobile phase consisted of $100 \mathrm{mM} \quad \mathrm{NaH}_{2} \mathrm{PO}_{4}, 10 \mathrm{mM} \mathrm{NaCl}, 0.1 \mathrm{mM}$ EDTA, $0.38 \mathrm{mM}$ sodium octanesulfonic acid, $10 \%$ methanol, and $\mathrm{pH}$ 3.5. The flow of the HPLC pump was adjusted to $1.0 \mathrm{~mL} / \mathrm{min}$ and the potential of the electrochemical detector, $0.4 \mathrm{~V}$ (Decade II, VT-03 electrochemical flow cell; Antec Leyden, The Netherlands). Chromatographic data were analyzed using Class-VP software (Shimadzu, Kyoto, Japan). NE and 5-HT were identified according to their elution time and quantified using calibration curves by the internal standard method (DHBA). The intra-assay coefficient of variation was less than $5 \%$ for all measured compounds. NE and serotonin levels were considered to reflect neurotransmitter stores in the synaptic vesicles ${ }^{49}$.

\section{BrdU administration}

Bromodeoxyuridine (BrdU; Sigma) was dissolved in 0.9\% $\mathrm{NaCl}$ and administered intraperitoneally at $75 \mathrm{mg} / \mathrm{kg}$, once a day for a total of 7 days ${ }^{38-40}$.

\section{Immunofluorescence}

Anesthetized mice $(80 \mathrm{mg} / \mathrm{kg}$ ketamine and $10 \mathrm{mg} / \mathrm{kg}$ xylazine) were submitted to transcardiac perfusion with $0.01 \mathrm{M}$ phosphate-buffered saline (PBS) and subsequently $2 \%$ paraformaldehyde (PFA). Brains were removed, fixed overnight in $4 \%$ PFA, and kept in a $30 \%$ sucrose solution at $4{ }^{\circ} \mathrm{C}$ during 3 days. Coronal $40-\mu \mathrm{m}$ brain sections were sliced through a cryostat and stored at $-22^{\circ} \mathrm{C}$ in PBSAF cryoprotectant solution (PBS, $20 \%$ sucrose, $15 \%$ ethylene glycol, $0.05 \% \mathrm{NaN}_{3}$ ). For each animal, we selected as many as possible $\mathrm{OB}$ slices, six slices of dorsal hippocampus $(1.70 \mathrm{~mm}$ to $-2.30 \mathrm{~mm}$ from Bregma) and six slices of ventral hippocampus $(-3.16 \text { to }-3.52 \mathrm{~mm} \text { from Bregma })^{50}$. Slices were washed sequentially in PBS, PBST, and $0.9 \%$ $\mathrm{NaCl}$. Subsequently, slices were incubated at $37^{\circ} \mathrm{C}$ in $2 \mathrm{M}$ $\mathrm{HCl}$ for $10 \mathrm{~min}$ and $3 \mathrm{M} \mathrm{HCl}$ for $30 \mathrm{~min}$, washed in $0.1 \mathrm{M}$ borate buffer. Slices were placed for $1 \mathrm{~h} 30 \mathrm{~min}$ in $5 \%$ normal goat serum and incubated for $72 \mathrm{~h}$ at $4{ }^{\circ} \mathrm{C}$ with either one of the following combinations: anti-BrdU (1:800; Abcam) and anti-NeuN (1:500; Millipore) or anti-BrdU (1:800; Abcam) and anti-GFAP (1:1000; Abcam), antiBrdU marked newborn cells, anti-NeuN labeled neurons, and anti-GFAP marked astrocyte cells. After, slices were washed in PBS and incubated for $90 \mathrm{~min}$ at room temperature with Alexa Fluor 488 (1:400, Invitrogen) and Alexa Fluor 568 (1:400, Invitrogen), washed in PBS, 
and mounted. Slices were fixed in Vectashield (Vector Laboratories) $^{39,40}$.

\section{Image acquisition and analysis}

Quantification of $\mathrm{BrdU}^{+} / \mathrm{NeuN}^{+}$and $\mathrm{BrDU}^{+} / \mathrm{GFAP}^{+}$ cells was achieved by counting the number of positive double-labeled cells using a $\times 40$ objective of an epifluorescence microscope (Zeiss) and Axiovision 4.8 software. Cells were considered double-labeled when colabeling with relevant morphology was seen throughout the extent of the cells and viewed in $x-y, x-z$, and $y-z$ cross-sections produced by orthogonal reconstructions from z-series. Cells were counted bilaterally, one by one, using Image Software (NIH, USA). The experimenter counted the cells blind to the condition. The exposure time for each filter was determined through the pixel saturation histogram, and the maximum possible number of pixels below the saturation limit was always used ${ }^{39,40}$.

Cell density was calculated using the DAPI immunostaining described above. Slice photos were acquired using an epifluorescence microscope (Zeiss) and Axiovision 4.8 software at $\times 40$ magnification. Each hippocampal region (CA1, CA3, and DG) and the internal and external granular layers of the $\mathrm{OB}$ were quantified within a rectangular area with a size between 2867 and $3959 \mu \mathrm{m}^{2}$. The measurement of the area and counting the number of cells were performed using ImageJ Software (NIH, USA). All density results were expressed as the cell density per $\mathrm{mm}^{2}$.

\section{Statistical analysis}

Sample size was estimated using the following formula: $n=S^{2} /(\mu A-\mu 0)^{2} \times(t \alpha+U \beta)^{2}$. Data were expressed as the mean \pm standard error of mean (SEM) with the exception of magentic resonance imaging (MRI) analysis data, which were expressed in median \pm interquartile range. Statistical analyses were performed using Graph Pad Prism 7 software. Two-way ANOVA followed by Bonferroni's multiple comparison test was used in social memory, forcedswimming test (FST), tail suspension test (TST), immunofluorescence, and \% of neurogenesis. Data from social memory were also analyzed by one-sample $t$-test, with 0.5 as the hypothetical value. Two-way repeated measures ANOVA followed by Bonferroni's multiple comparison test was used in sucrose preference and weight gain. Other results were analyzed by unpaired Student $t$-test.

\section{Results}

\section{SI does not compromise social recognition memory in female mice}

There is evidence suggesting that SI affects males and females differentially ${ }^{51}$. Therefore, before assessing whether the social memory deficit caused by SI in male mice $^{36-38}$ is accompanied by depressive-like behavior, we tested female mice in the social recognition task after
1 week of SI. We conducted experiments (Fig. 1a) to test short (STM, Fig. 1b) and long-term (LTM, Fig. 1c) social memory in female mice. We chose to test STM because it was the first time we tested females, and we know that SI did not compromise STM in males ${ }^{36-38}$. In the STM, there was no difference between groups $\left(t_{(13)}=0.5, p=\right.$ 0.58 ). Additionally, both groups explored less the juvenile during the test (one-sample $t$-test: control: $t_{(7)}=6, p=$ 0.0005 ; social isolation: $t_{(6)}=2.6, p=0.03$ ). Similar results were observed for LTM. No difference between groups was detected $\left(t_{(13)}=1.7, p=0.1\right)$. However, control and social isolated female mice explored less the juvenile during testing (one-sample $t$-test: control: $t_{(6)}=3.11, p=$ 0.02 ; social isolation: $\left.t_{(7)}=11.8, p<0.0001\right)$. Taken together, our results indicate that 1 week of SI did not affect social memory in female Swiss mice. We also tested females in the forced swim test (FST) and found that 1 week of SI induced depressive-like behavior in females (Fig. 1d: $t_{(28)}=3.9, p=0.0005$ ), as expected. However, in order to pursuit our initial question, which is to investigate whether the memory deficit and depressive behavior present a common neural mechanism in the context of SI, we conducted the experiments using male, since SI did not affect social memory in female mice.

\section{Depressive-like behavior induced by $\mathrm{SI}$ is rescued by the acute treatment with fluoxetine or desipramine}

Thus, we evaluated the effect of SI on depressive-like behavior in male mice and also the effect of antidepressants (Fig. 1e). Two-way ANOVA followed by multicomparison test showed higher immobility time in SI mice and that fluoxetine (FLX) prevented this behavior to happen (Fig. 1f; Interaction: $F_{(2,42)}=4.5, p=0.01$; House condition: $F_{(1,42)}=11.2, p<0.001$; Treatment: $\left.F_{(2,42)}=40.6, p<0.0001\right)$. Similar results were observed for desipramine (DES) (Fig. 1g; Interaction: $F_{(2,42)}=0.04$, $p=0.95$; House condition: $F_{(1,42)}=28, p<0.0001$; Treatment: $\left.F_{(2,42)}=17.7, p<0.0001\right)$. Furthermore, SI effect on FST may not be attributed to locomotor activity, since SI and control groups behaved similarly in the open field (Control: $1844 \pm 482.1 \mathrm{~cm}$; Social isolation: $1810 \pm$ $345.6 \mathrm{~cm}$; unpaired $t$-test: $t_{(14)}=0.16, p=0.87$ ).

\section{Long-term social memory impairment caused by $\mathrm{SI}$ is rescued by chronic treatment with fluoxetine}

Given that SI induces depressive-like behavior and social recognition memory deficit, we raised the question as to whether these two effects are related. Thus, we tested the ability of antidepressants to rescue the social recognition memory impaired by SI (Fig. 1h). The acute treatment with fluoxetine (FLX) or desipramine (DES) (Fig. 1i) produced a main effect of house condition $\left(F_{(1,42)}\right.$ $=46, p<0.0001)$, but not of treatment $\left(F_{(2,42)}=2.6, p=\right.$ $0.08)$ or interaction between factors $\left(F_{(2,42)}=2, p=0.1\right)$. 


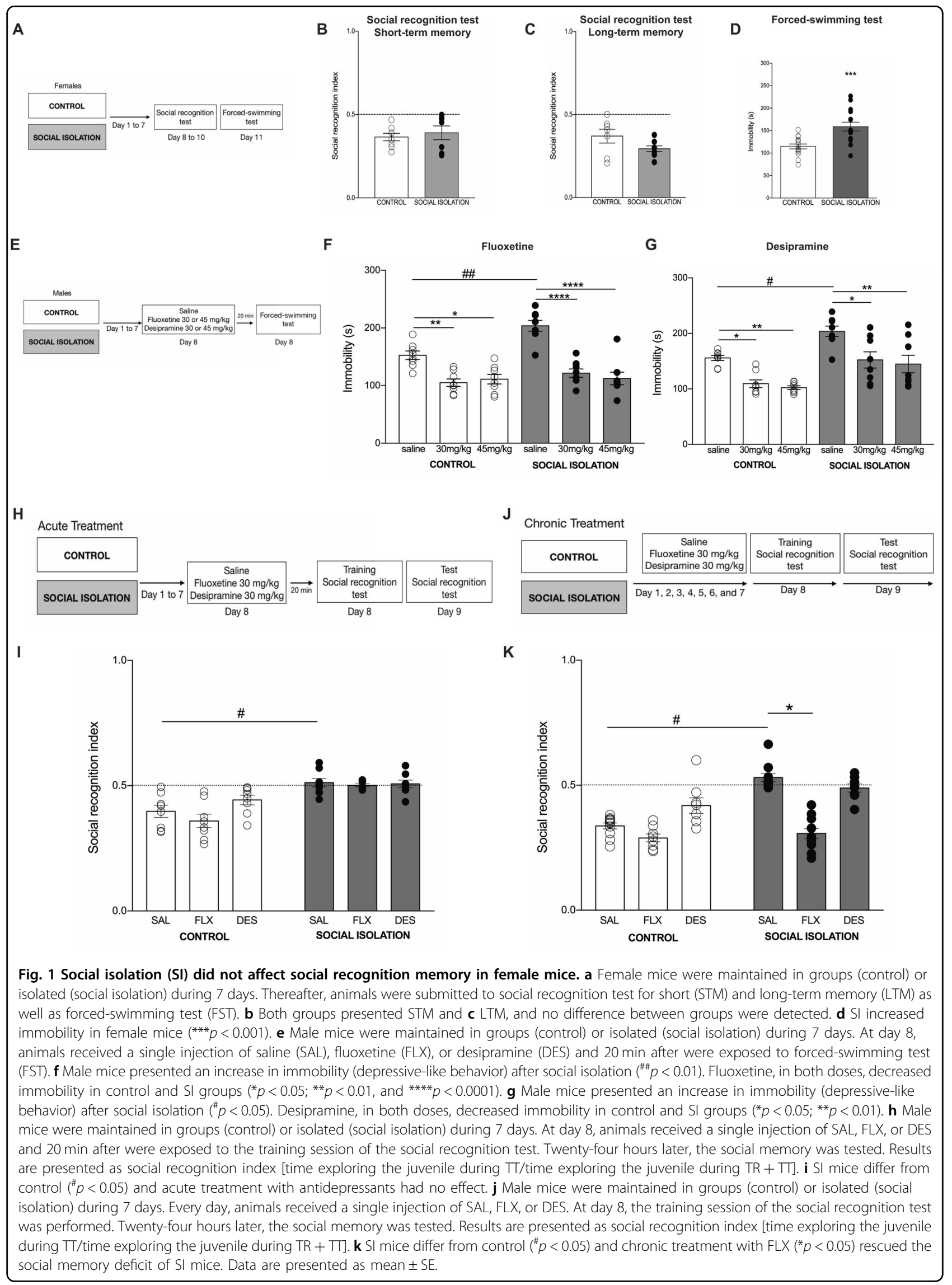


Post hoc analysis indicated a difference between control and SI treated with saline, confirming our previous results, but no effect of antidepressants was observed. Complementary analysis with one-sample $t$-test confirmed that the social recognition index of SI mice did not differ from chance (Saline: $t_{(7)}=0.7, p=0.49$; FLX: $t_{(7)}=$ $0.2, p=0.8$; DES: $\left.t_{(7)}=0.4, p=0.6\right)$. And as expected, all control groups showed a social recognition index fitting a regular social memory (Saline: $t_{(7)}=4.1, p=0.004$; FLX: $t_{(7)}=5.2, p=0.001$; DES: $\left.t_{(7)}=3, p=0.01\right)$. Therefore, acute treatment with FLX or DES did not rescue the memory deficit of SI mice.

Next, we verified whether a chronic treatment would be efficient in rescuing the social recognition memory deficit in SI mice (Fig. 1j). Two-way ANOVA revealed interaction between factors $\left(F_{(2,50)}=12.3, p<0.0001\right)$ and a main effect for house condition $\left(F_{(1,50)}=36.8, p<0.0001\right)$ and treatment $\left(F_{(2,50)}=39.6, p<0.0001\right)$. Then again, Bonferroni's post-test analysis showed a difference between control and SI mice. Additionally, SI mice treated with FLX presented a lower social recognition index compared to the SI-saline group (Fig. 1k), indicating they have LTM. As expected, all control groups showed a social recognition index fitting a regular social memory (Saline: $t_{(10)}=$ 13.6, $p<0.0001$; FLX: $t_{(7)}=13.4, p<0.0001$; DES: $t_{(7)}=$ 2.6, $p=0.03)$. SI mice presented the memory deficit (Saline: $\left.t_{(9)}=1.9, p=0.08\right)$. Interestingly, FLX $\left(t_{(10)}=9.7\right.$, $p<0.0001)$, but not DES $\left(t_{(7)}=0.6, p=0.5\right)$ treated SI mice showed a recognition index different from chance.

We also evaluated the effect of chronic treatment with FLX and DES in FST [Data showed as mean \pm SEM: control $(n=11,159.6 \pm 16.6 \mathrm{~s})$; control $+\mathrm{FLX}(n=8,101.3 \pm$ $14.9 \mathrm{~s})$; control + DES $(n=8,109.6 \pm 16.5 \mathrm{~s})$; SI $(n=10$, $201.9 \pm 21.2 \mathrm{~s}) ; \mathrm{SI}+\mathrm{FLX}(n=11,109.6 \pm 11.4 \mathrm{~s}) ; \mathrm{SI}+\mathrm{DES}$ $(n=8,142.3 \pm 31 \mathrm{~s})]$. Two-way ANOVA showed an interaction $\left(F_{(2,50)}=3.9, p=0.02\right)$ between factors and a main effect of house condition $\left(F_{(1,50)}=28.7, p<0.0001\right)$ and treatment $\left(F_{(2,50)}=81.7, \quad p<0.0001\right)$. Multicomparison test confirmed the antidepressant effect of FLX and DES in control animals $(p<0.0001)$ and showed that FLX and DES decreased immobility in SI mice $(p<$ $0.0001)$. We also reproduced the depressive-like behavior in SI mice $(p<0.0001)$.

\section{Enriched environment prevents the depressive-like state promoted by SI}

We have shown that SI induced depressive-like behaviors and impaired social recognition memory. Antidepressants recovered the depressive-like behavior, but only the chronic treatment with fluoxetine was able to counteract SI effect on social memory. As we showed before $^{38}$ that enriched environment (EE) rescues the deleterious effect of SI on social memory, here we tested whether EE would also act as antidepressant.
Appetite and weight changes are common, though inconstant physiological markers for depression in humans ${ }^{12}$. In our model, we found a profound weight loss along the 7 days of isolation that was completely blocked by the $\mathrm{EE}$ (Interaction: $F_{(21,196)}=1.3, p=0.1$; Time: $F_{(7,196)}=4.1, p=0.0003$; House condition: $F_{(3,28)}=33.7$, $p<0.0001$ ) (Fig. 2a). As showed in Fig. 1, SI mice spend more time immobile during the FST (Fig. 2b). Interestingly, EE was antidepressant, but only for SI mice (Interaction: $F_{(1,28)}=3.2, \quad p=0.08$; House condition: $F_{(1,28)}=11, p=0.002$; Social Stimulus: $F_{(1,28)}=14.5, p=$ $0.0007)$. We also tested animals in the TST and found similar results. SI increased immobility, while EE prevented such effect, without changing behavior of control animals (Interaction: $F_{(1,24)}=6.1, p=0.02$; House condition: $F_{(1,24)}=8.8, p=0.006$; Social stimulus: $F_{(1,24)}=10.2$, $p=0.003$ ) (Fig. 2c).

Decreased ability to experience pleasure is another core symptom of depression ${ }^{12,52,53}$. Therefore, we tested whether SI would affect hedonic behavior in sucrose preference test. Socially isolated mice did not preferer sucrose in the first $2 \mathrm{~h}$ of testing, while EE normalize such behavior (Interaction: $F_{(15,40)}=2.3, p=0.004$; Time: $F_{(5,140)}=3.6, p=0.004$; House condition: $F_{(3,28)}=4.7$, $p=0.008$ ) (Fig. 2d).

\section{Decreased NE levels and reduced $O B$ volume in socially isolated mice}

To further characterize the SI effect on brain function, we sought to investigate whether one week of SI in adulthood would alter morphological and neurochemical features related to depressive behaviors. One interesting aspect about acute major depressive patients is the presence of a smaller $\mathrm{OB}$ volume ${ }^{13}$, which is in accordance with the bulbectomy in rodents being proposed as an animal model for depression ${ }^{54,55}$. To address this question, we submitted mice to MRI after SI (Fig. 3a). We found that mice that underwent to SI have reduced OBs compared to control (Fig. 3b: $t_{(8)}=4.5, p=0.002$ ). We also estimated cell density, but found no difference between groups in both external $\left(t_{(18)}=1.0, p=0.2\right)$ and internal $\left(t_{(18)}=1.9\right.$, $p=0.06$ ) granular layer of the OB (Fig. 3c).

Neurochemical unbalance may also be present in humans ${ }^{18,19}$ and rodents ${ }^{21,35-37}$ under a depressive state. Particularly serotonin (5-HT) and NE levels may be disturbed in those situations ${ }^{18,20,36}$. Thus, we verified whether SI would alter $\mathrm{NE}$ and 5-HT levels in $\mathrm{OB}$ homogenates. SI decreased NE levels in the OB (Fig. 3d: $\left.t_{(11)}=2.2, p=0.04\right)$, while no effect of SI was observed in 5-HT levels (Fig. 3e: $t_{(11)}=1.3, p=0.1$ ).

\section{SI reduces NE and serotonin in the dorsal hippocampus}

In addition to the $\mathrm{OB}$, the hippocampus is also sensitive to the effects of chronic depression ${ }^{56,57}$. Therefore, we 

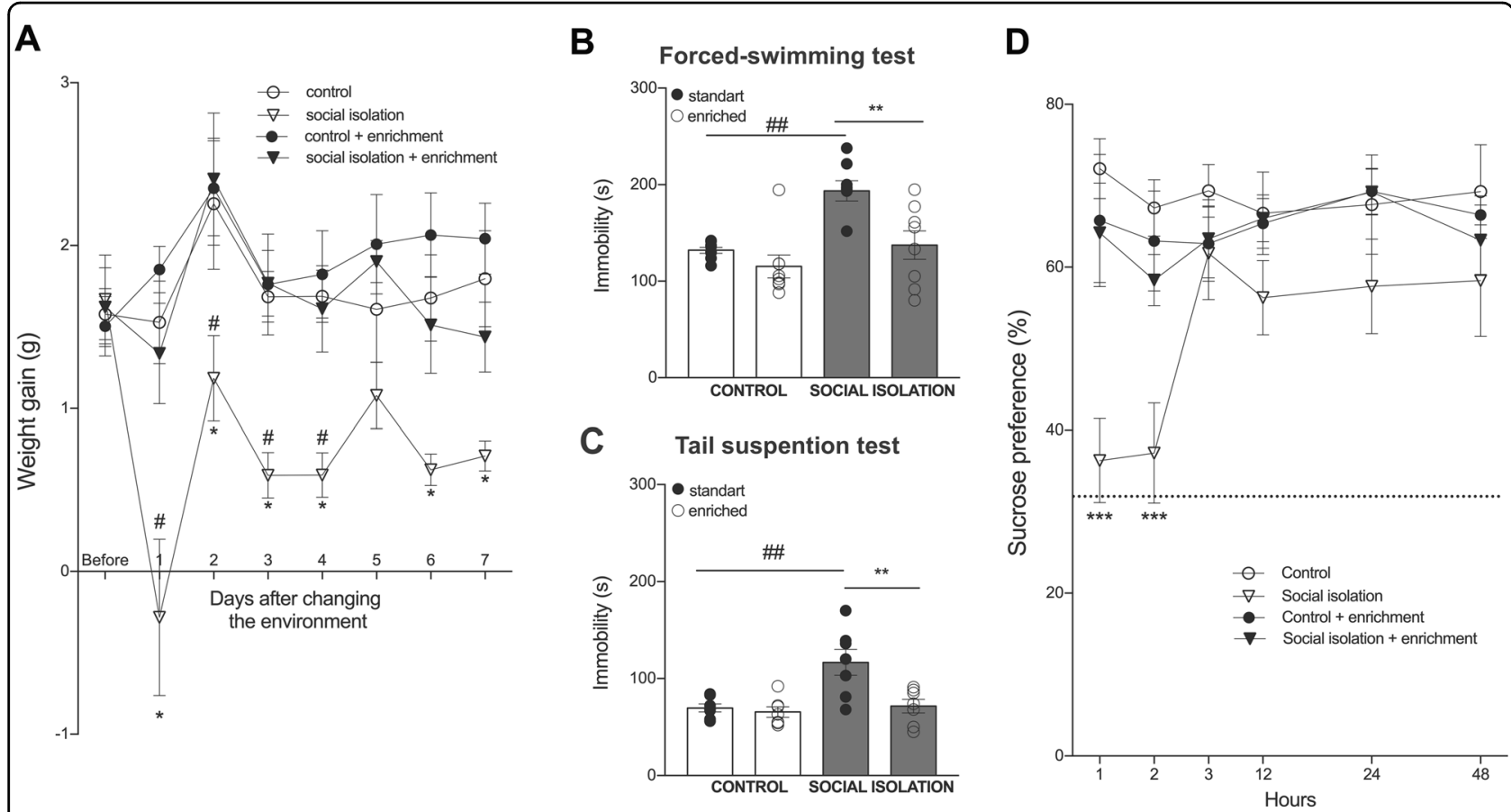

Fig. 2 Antidepressant effect of enriched environment. a Loss of weight caused by social isolation was prevented by enriched enrichment. $p<$ 0.05 indicates difference within the group and ${ }^{\#} p<0.05$ indicates difference between groups. $\mathbf{b}, \mathbf{c}$ Depressive-like behavior in social isolated mice was prevented by the enriched environment $\left(^{*}\right.$ and $\left.{ }^{\# \#} p<0.01\right)$. d Social isolated mice avoid sucrose solution in the first two hours of exposure $\left(^{* * *} p<\right.$ 0.001), while enriched environment prevented such behavior. Data are presented as mean $\pm \mathrm{SE}$.

investigated whether the SI would affect the volume, as well as the NE and 5-HT levels in dorsal (dHIP) and ventral hippocampus (vHIP).

The MRI analysis (Fig. 3f) showed no difference between groups regarding the volume of the dHIP (Fig. $\left.3 g: t_{(10)}=0.9, p=0.3\right)$. Cell density (Fig. $\left.3 \mathrm{~h}\right)$ in CA1 $\left(t_{(18)}\right.$ $=0.1, p=0.8)$ and CA3 $\left(t_{(18)}=1.6, p=0.1\right)$ was similar between groups, though in the DG there was a tendency for SI to reduce cell density $\left(t_{(18)}=2.0, p=0.05\right)$. Interestingly, SI decreased NE (Fig. 3i: $t_{(12)}=2.5$, $p=0.02$ ) and 5-HT (Fig. 3j: $t_{(12)}=2.7, p=0.01$ ) in the dHIP.

In vHIP (Fig. 3k) we also did not find difference between groups regarding the volume (Fig. 3l: $t_{(10)}=0.6, p=0.5$ ). Furthermore, no difference between groups was observed in cell density measured in CA1 $\left(t_{(18)}=0.5, p=0.5\right)$, CA3 $\left(t_{(18)}=0.4, p=0.6\right)$, and DG $\left(t_{(18)}=1.0, p=0.3\right)$ (Fig. $3 \mathrm{~m}$ ). In addition, neither the NE (Fig. 3n: $t_{(12)}=0.9, p=$ 0.3 ) nor the 5-HT levels (Fig. 3o: $t_{(10)}=1, p=0.3$ ) were altered after SI.

\section{Fluoxetine increased cell proliferation in the dHIP of SI mice}

Previous studies from our group showed that enriched environment rescued the memory deficit of SI mice in a neurogenesis-dependent manner ${ }^{38}$. Antidepressants, such as fluoxetine (FLX), are well known to modulate neurogenesis $^{58-60}$. Thus, we verified the effect of antidepressants in combination with SI on neurogenesis.

We analyzed dHIP (Fig. 4a, b) and vHIP (Fig. 4c, d). In dHIP, only FLX increased cell proliferation in both control and SI mice, even though its effect was less expressive in SI mice (Interaction: $F_{(2,54)}=1.2, p=0.28$; Treatment: $F_{(2,54)}=36.9, p<0.0001$; House condition: $F_{(1,54)}=13.3$, $p=0.0006$ ) (Fig. 4e). As predicted, FLX increased neurogenesis (Fig. 4f); however, no effect on SI mice was observed (Interaction: $F_{(2,24)}=1.2, p=0.29$; Treatment: $F_{(2,24)}=15.9, p<0.0001$; House condition: $F_{(1,24)}=14.7$, $p=0.0008$ ). Astrogenesis (Fig. $4 \mathrm{~g}$ ) was unchanged in all conditions evaluated (Interaction: $F_{(2,24)}=0.03, p=0.9$; Treatment: $F_{(2,24)}=1.3, p=0.26$; House condition: $F_{(1,24)}$ $=0.6, p=0.4)$.

\section{SI decreased neurogenesis in the ventral hippocampus}

Motivated by vHIP role on social behavior ${ }^{61-64}$ and depression $^{65-67}$ we investigated whether SI would affect cell proliferation, neurogenesis, and astrogenesis in this area. SI decreased cell proliferation, while FLX and DES increased it. In control animals, only FLX was effective in increasing cell proliferation (Interaction: $F_{(2,54)}=7.2, p=$ 0.001; Treatment: $F_{(2,54)}=61.9, p<0.0001$; House condition: $\left.\quad F_{(1,54)}=801.2, \quad p<0.0001\right) \quad$ (Fig. 4h). Both 


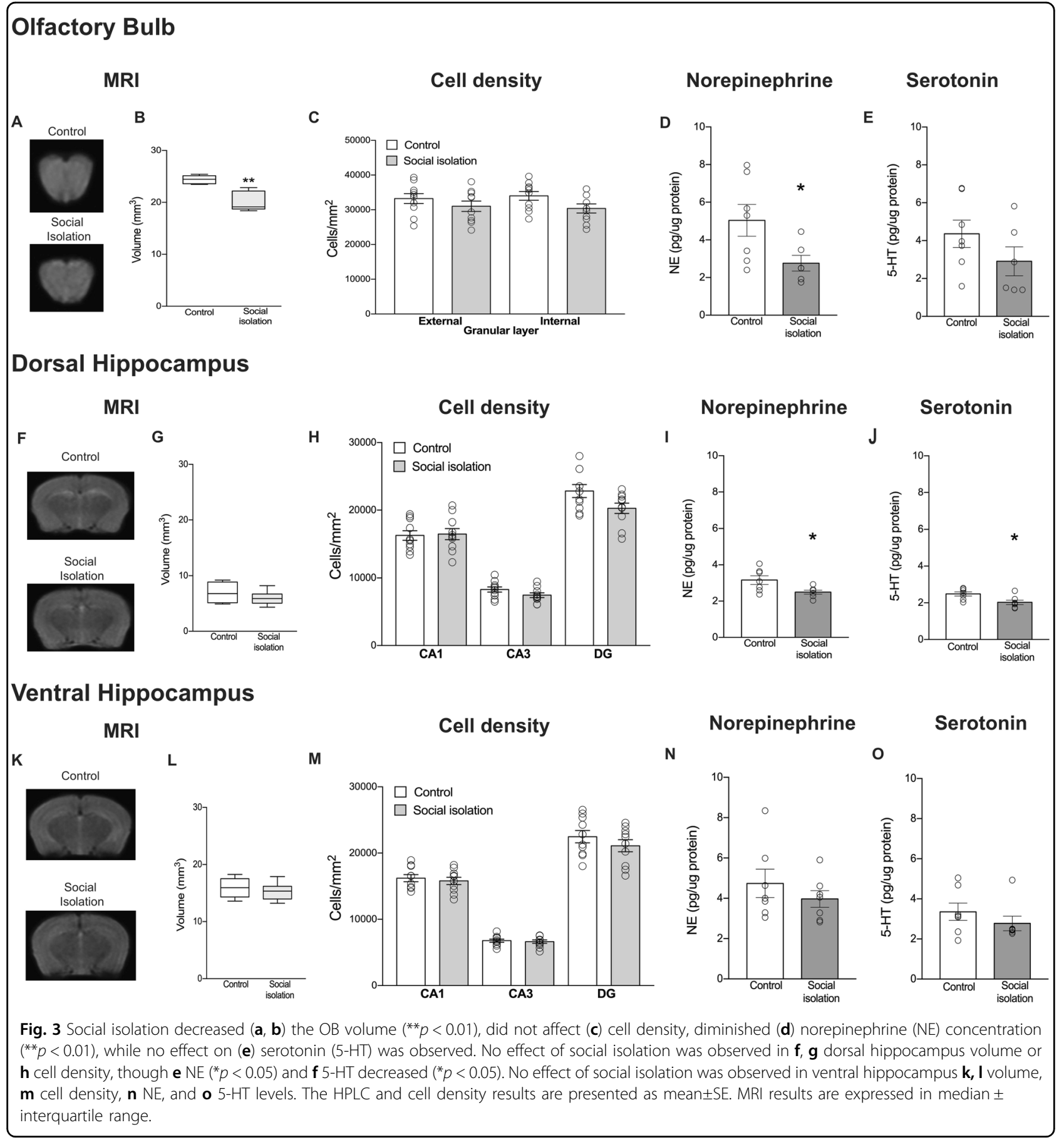

antidepressants increased neurogenesis in control mice (Fig. 4i). Similar pattern was observed in SI mice, though the neurogenesis level was lower (Interaction: $F_{(2,24)}=$ $0.63, p=0.54$; Treatment: $F_{(2,24)}=71.8, p<0.0001$; House condition: $\left.F_{(1,24)}=168.9, p<0.0001\right)$. In general, astrogenesis was decreased in SI mice, though post hoc analysis failed to detect statistical difference between groups (Interaction: $F_{(2,24)}=0.06, p=0.9$; Treatment: $F_{(2,24)}=$
$0.3, p=0.6 ;$ House condition: $\left.F_{(1,24)}=5.1, p=0.03\right)$ (Fig. 4j).

Fluoxetine rescued neurogenesis in $\mathrm{OB}$, suppressed by $\mathrm{SI}$

Finally, we evaluated the effect of antidepressants and SI on the OB (Fig. 5a) neurogenesis, specifically the granular layer (Fig. 5b). SI decreased cell proliferation (Interaction: $F_{(2,56)}=3.2, p=0.04$; Treatment: $F_{(2,56)}=0.2, p=0.7$; 


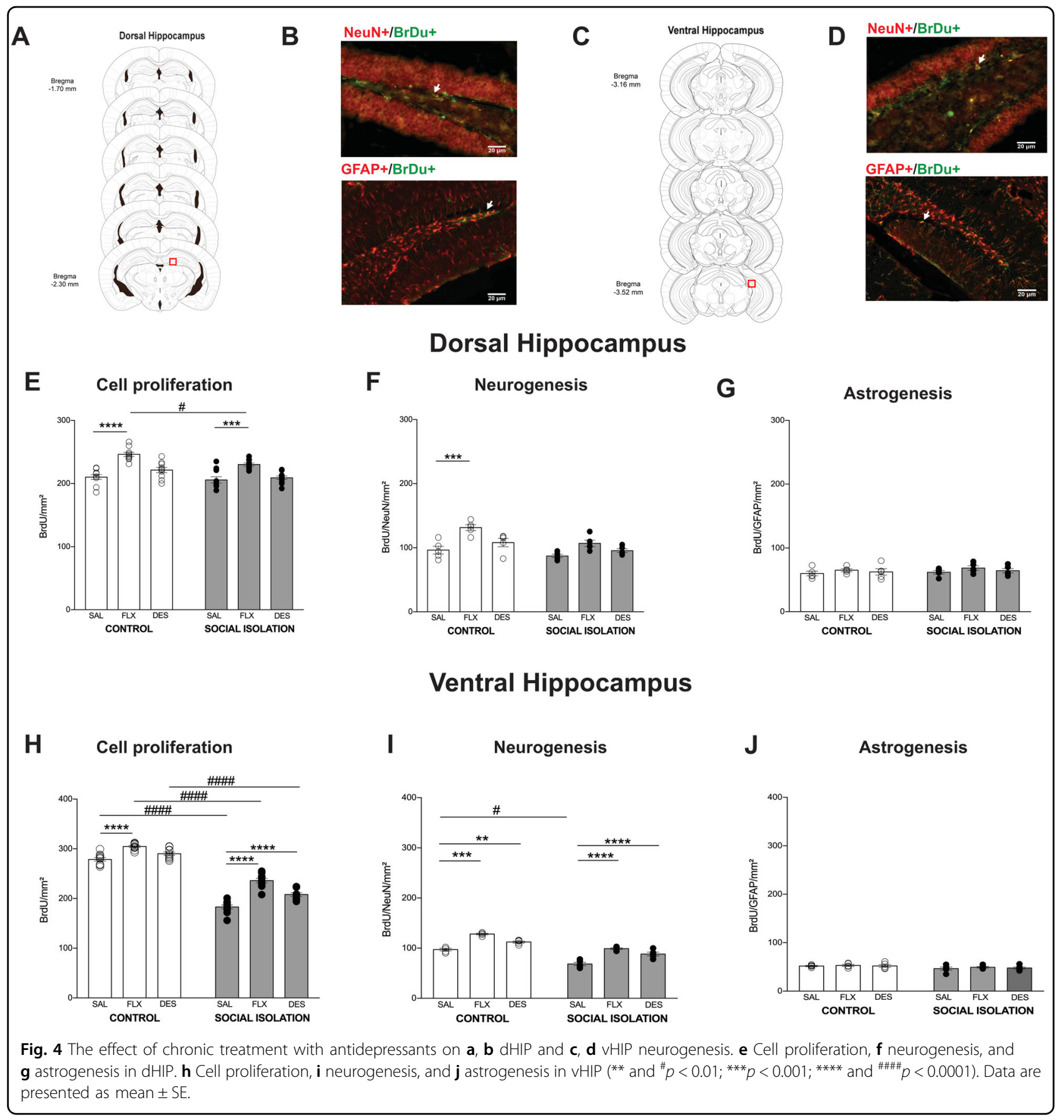

House condition: $\left.F_{(1,56)}=3.9, p=0.05\right)$ (Fig. 5c). Similar result was observed for neurogenesis, adding the fact that FLX blocked the SI effect (Interaction: $F_{(2,25)}=0.9, p=$ 0.9; Treatment: $F_{(2,25)}=9.6, p=0.0008$; House condition: $F_{(1,25)}=19.5, p=0.0002$ ) (Fig. 5d). Interestingly, differently from the hippocampus, FLX increased astrogenesis, though statistical significance was reached only for control animals (Interaction: $F_{(2,25)}=0.5, p=0.5$; Treatment: $F_{(2,25)}=16.1, p<0.0001$; House condition: $F_{(1,25)}=10, p$ $=0.004)$ (Fig. 5e).
Under SI, fluoxetine increases region-dependent neurogenesis

To verify whether a neurogenesis niche would be more sensitive to antidepressants than others, and consequently estimate a possible relationship between the neurogenesis and the behavioral output, we calculated the percentage of increase in neurogenesis compared to saline in both control and social isolated animals. Figure $5 \mathrm{f}$ depicts the DES results. There was interaction (house condition and brain region, $\left.F_{(2,25)}=5.3, p=0.01\right)$, as well as main effect 
A

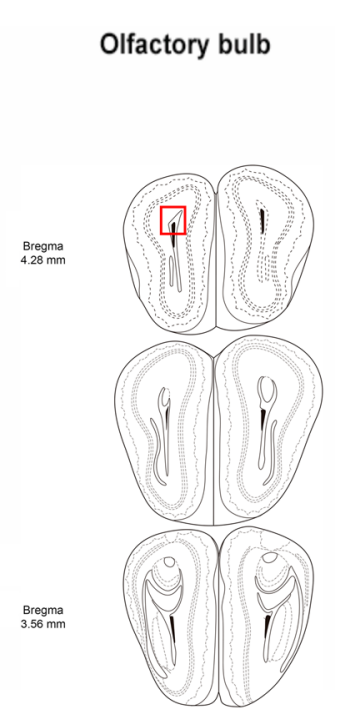

B $\mathrm{NeuN+/BrDu+}$

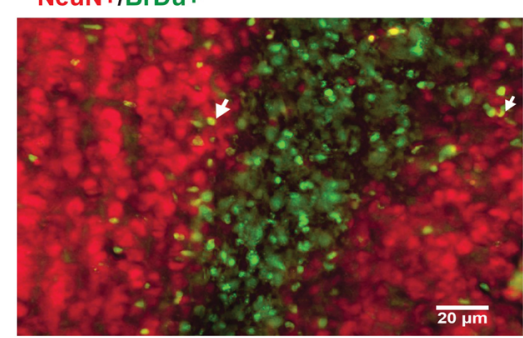

GFAP+/BrDu+

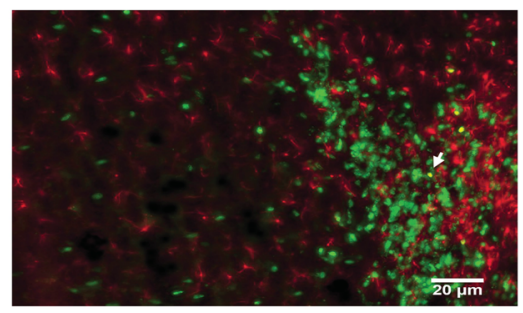

$\mathbf{F}$

Desipramine

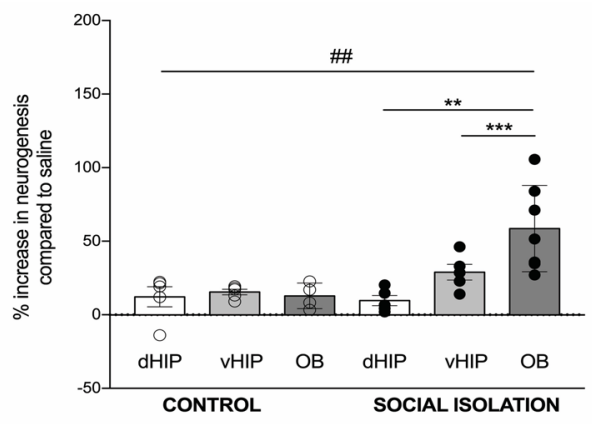

\section{Cell proliferation}

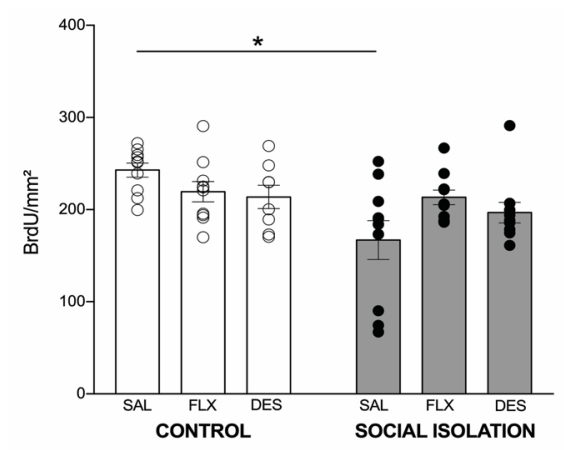

D
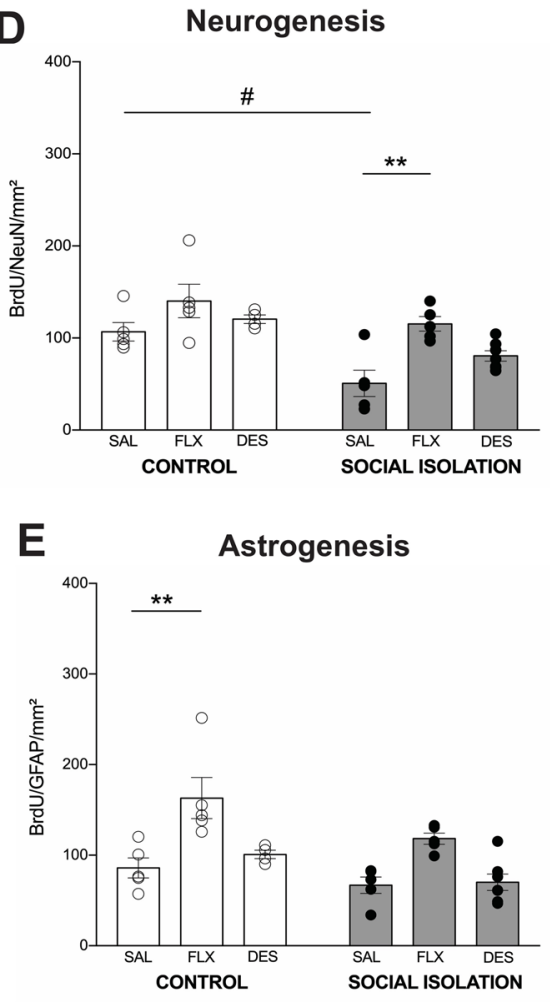

G

\section{Fluoxetine}

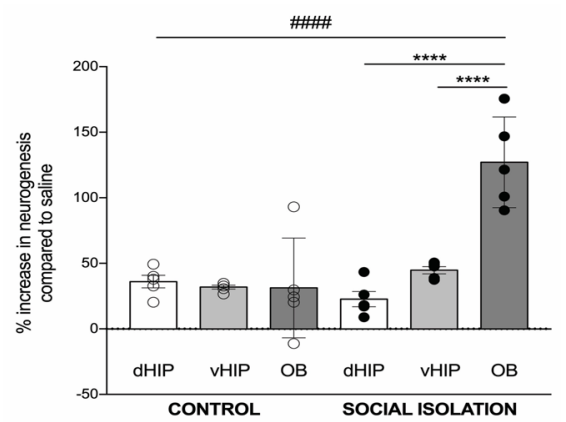

Fig. $\mathbf{5}$ The effect of chronic treatment with antidepressants on $\mathbf{a}$, $\mathbf{b}$ olfactory bulb neurogenesis. $\mathbf{d}$ Cell proliferation, e neurogenesis, and $\mathbf{f}$ astrogenesis. Olfactory bulb (OB) responded better than dorsal (dHIP) and ventral (vHIP) hippocampus to $\mathbf{g}$ desipramine and $\mathbf{h}$ fluoxetine chronic

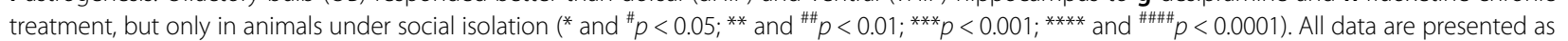
mean $\pm \mathrm{SE}$. 
for both factors (House condition: $F_{(1,25)}=9.3, p=0.005$; Brain region: $\left.F_{(2,25)}=5.4, p=0.01\right)$. Post hoc analysis showed that in SI mice, neurogenesis in the $\mathrm{OB}$ was higher than in the dHIP and vHIP. Furthermore, a difference between control and SI was observed only in the OB. No difference between areas was observed in the control group. Regarding FLX, two-way ANOVA revealed interaction (house condition and brain region, $F_{(2,24)}=$ 16.3, $p<0.0001)$, as well as main effect for both factors (House condition: $F_{(1,24)}=15.2, p<0.0001$; Brain region: $F_{(2,24)}=14.1, p<0.0001$ ) (Fig. 5g). Multiple comparison test detected that the increase in neurogenesis in the $\mathrm{OB}$ of SI mice was higher compared to dHIP and vHIP. It was also higher compared to OB from control animals. As for DES, no difference between areas was observed in the control group.

\section{Discussion}

The ubiquitous manifestation of memory failures in depressed patients suggests that some level of overlap may exist in the neural mechanisms of depression and episodic memories. Yet, current understanding about the neural mechanisms of memory disruption in depression is limited. Here, we showed that social recognition memory deficit and depressant phenotype emerge concomitantly when adult Swiss mice are socially isolated for 7 days, suiting an appropriate model to investigate the mechanisms of memory disruption in depression.

It has been evidenced that social contact during specific phases of development is determinant for adult rodents to maintain stable emotional behaviors ${ }^{68-70}$. Here, we complemented this point of view by showing that Swiss mice behave according to a depressive phenotype, after being isolated from co-specifics for 7 days in the adulthood (SI mice).

C57/BL6 mice are usually more resistant to models that induce depressive-like behaviors ${ }^{71,72}$. On contrary, 1 week of SI is sufficient to induce social memory deficits in both C57/BL6 (ref. ${ }^{38}$ ) and Swiss mice ${ }^{38}$. We chose to focus on Swiss mice in the present study to keep unified the SI duration to induce both memory deficit and depressivelike behavior. We found that adult SI mice gained less weight, as it was observed in juvenile Swiss mice submitted to isolation ${ }^{70}$. In contrast, no change in body weight was observed in C57/BL6 mice isolated for 28 days in the adulthood ${ }^{73}$. Intriguingly, appetite and weight changes are often the most discriminating symptoms to diagnose human depression subtypes ${ }^{74,75}$. In fact, the symptoms of depression disorders include significant weight loss or weight gain ${ }^{76}$. Supporting this apparent paradox, it was showed an opposite activation of the midinsula from depressed subjects with appetite-increased and appetite-decreased, in response to food images ${ }^{77}$. Therefore, our study proposes that 7 days of SI in Swiss mice represent an ideal animal model to better comprehend the neural basis of weight loss in depression.

Lower concentrations of NE and serotonin $(5-\mathrm{HT})$ in the brain ${ }^{18-20,23-25}$ along with the effectiveness of antidepressant drugs ${ }^{21,22}$ support the monoaminergic hypothesis of depression. Here, SI reduced NE in the OB and the dorsal hippocampus (dHIP), and 5-HT in the dHIP. Furthermore, fluoxetine (30 and $45 \mathrm{mg} / \mathrm{kg}$ ) and desipramine (30 and $45 \mathrm{mg} / \mathrm{kg}$ ) decreased immobility time of SI mice in the FST. Altogether, these results suggest that a monoaminergic unbalance may play a role on the depressive behaviors caused by SI.

Alternatively, the neural plasticity theory of depression proposes neurogenesis as a key element in the pathogenesis of depression ${ }^{78}$. In other words, neurogenesis in the hippocampus decreases in depression, while antidepressants effectiveness depends on neurogenesis upregulation $^{79}$. Here, SI decreased cell proliferation and neurogenesis in the vHIP, while both antidepressants restored neurogenesis in this very same region. Interestingly, no changes in NE and 5-HT were observed in vHIP. Therefore, vHIP presents as the ideal neural substrate for the neural plasticity theory of depression in the context of ST. In fact, this assumption agrees with the notion that dHIP and vHIP functions are associated with memory and affective behaviors, respectively ${ }^{80-82}$.

DES and FLX have distinct mechanism of action, while the former inhibits NE reuptake ${ }^{83,84}$, the second selectively inhibits serotonin reuptake ${ }^{85,86}$. FLX effect in increasing neurogenesis is well grounded in the literature $^{87-89}$. Interestingly, one study that measured neurogenesis based on specific cell types showed that FLX effects depend on the dorsoventral axis of the hippocampus $^{27}$. However, in the present study we used a general neurogenesis marker and found a similar effect of FLX in dHIP and vHIP neurogenesis.

Compared to FLX, DES effect on neurogenesis has been less explored. It was showed that DES is effective in increasing neurogenesis in stress-induced models ${ }^{90}$ and abstinence following alcohol drinking ${ }^{91}$. Here, the treatment with DES was able to increase neurogenesis in the ventral hippocampus of both control and social isolated mice.

In the context of SI, we propose that the neurogenic niche determines whether the depressive phenotype and the social memory deficit are connected or not. As suggested before, and supported by our results, affective behaviors are modulated by the neurogenesis levels in the vHIP. On the other hand, we suggest that social memory is particularly sensitive to neurogenesis in the dHIP, compared to vHIP and $\mathrm{OB}^{40}$. In fact, neither fluoxetine or desipramine substantially affected neurogenesis in the dHIP.

The unique experimental condition wherein social memory deficit and depressive behavior caused by SI were 
recovered was after chronic treatment with fluoxetine. Thus, we predicted that the region wherein the fluoxetine-dependent increase in neurogenesis was higher is the region with a crucial role in both cognitive and emotional impairments, caused by ST. Therefore, our results support a pivotal role for the $\mathrm{OB}$. The percentage increase in neurogenesis caused by FLX was about two times higher in the OB, compared to dHIP and vHIP. Nevertheless, one could argue that OB neurogenesis was also more affected by DES, compared to other neural substrates, although desipramine did not improve social memory. However, it is worth noticing that the magnitude of increase was of about $50 \%$ and $100 \%$ after DES and FLX, respectively. Furthermore, there was no regiondependent effect of FLX or DES in the control group, suggesting that the antidepressants efficiency on increasing neurogenesis may be sensitive to the environment where the animal lives. Interestingly, a recent study showed that the efficiency of FLX on rescuing the depressive phenotype caused by chronic stress depends on whether the animal is kept in enriched environment or not during the treatment ${ }^{90}$.

Compared to the hippocampus, there are only few studies showing that FLX increases neurogenesis in the $\mathrm{OB}^{87}$, despite its densely serotoninergic innervation from the raphe nuclei ${ }^{92}$. Equally less investigated is the function of serotoninergic terminals in the OB. It was showed that the stimulation of raphe nuclei regulates odor inputs in the $\mathrm{OB}^{93}$ and improves pattern separation of odors in mice $^{94}$. Consistent with our results, corticosterone treated-mice are depressed, displaying olfactory memory deficit and decreased OB-neurogenesis, and all these effects were recovered by chronic FLX treatment ${ }^{87}$.

Hippocampus sends direct excitatory inputs to the olfactory system ${ }^{95,96}$ and this top-down modulation is important to predict, expect, and retrieve memories from previous experiences ${ }^{97-99}$. However, such projections are not equally distributed along the anterior-posterior tract. For example, pyramidal neurons from the ventral hippocampus project massively to medial anterior olfactory nucleus, while dorsal innervate increasingly more lateral positions ${ }^{100}$. We showed recently that $\mathrm{OB}$ theta oscillations drive dorsal hippocampus gamma amplitude during long-term social memory retrieval. This OB-dHIP coupling was impaired in SI mice during memory retrieval ${ }^{37}$. Taken together, we may speculate that FLX has recovered the social memory deficit by reinstating OB-dHIP coupling, though a new study is needed to test this hypothesis.

Finally, we tested whether enriched environment would be as effective as the fluoxetine and desipramine on rescuing SI mice depressive-like behavior. Our results showed a consistent antidepressant effect of enriched environment. As we already demonstrated a cause-effect relationship between social memory and neurogenesis in SI mice ${ }^{38}$, we may suggest that neurogenesis is possibly playing a role on the antidepressant effect of enriched environment as well.

\section{Acknowledgements}

This study was supported by the Conselho Nacional de Desenvolvimento Científico e Tecnológico (PVE 401273/2014), Coordenação de Aperfeiçoamento de Pessoal de Nível Superior (Procad 88881.068460/2014-01), and Fundação de Amparo à Pesquisa do Estado de Minas Gerais (APQ01396-15). R.E.S., E.M.A.M.M., M.F.D.M. and G.S.P. were supported by a fellowship from CNPq. L.O.G. was supported by an exchange fellowship from CNPq (PVE).

\section{Author details}

${ }^{1}$ Núcleo de Neurociências, Universidade Federal de Minas Gerais, Belo Horizonte, Brazil. ${ }^{2}$ Centro de Tecnologia e Pesquisa em Magneto Ressonância, Programa de Pós-Graduação em Engenharia Elétrica, Universidade Federal de Minas Gerais, Belo Horizonte, Brazil. 'aboratório de Endocrinologia, Departamento de Fisiologia e Biofísica, Instituto de Ciências Biológicas, Universidade Federal de Minas Gerais, Belo Horizonte, Brazil

Conflict of interest

The authors declare that they have no conflict of interest.

\section{Publisher's note}

Springer Nature remains neutral with regard to jurisdictional claims in published maps and institutional affiliations.

Received: 1 May 2019 Revised: 18 December 2019 Accepted: 2 January 2020

Published online: 27 January 2020

\section{References}

1. Beller, J. \& Wagner, A. Disentangling loneliness: differential effects of subjective loneliness, network quality, network size, and living alone on physical, mental, and cognitive health. J. Aging Health 30, 521-539 (2018).

2. Stickley, A. \& Koyanagi, A. Physical multimorbidity and loneliness: a population-based study. PLoS One 13, e0191651 (2018).

3. Campagne, D. M. Stress and perceived social isolation (loneliness). Arch. Gerontol. Geriatr. 82, 192-199 (2019).

4. Heikkinen, R. L. \& Kauppinen, M. Depressive symptoms in late life: a 10-year follow-up. Arch. Gerontol. Geriatr. 38, 239-250 (2004).

5. Cacioppo, J. T. et al. Loneliness as a specific risk factor for depressive symptoms: cross-sectional and longitudinal analyses. Psychol. Aging 21, 140-151 (2006).

6. Cacioppo, J. T., Hawkley, L. C. \& Thisted, R. A. Perceived social isolation makes me sad: 5-year cross-lagged analyses of loneliness and depressive symptomatology in the Chicago Health, Aging, and Social Relations Study. Psychol. Aging 25, 453-463 (2010).

7. VanderWeele, T. J. et al. A marginal structural model analysis for loneliness: implications for intervention trials and clinical practice. J. Consult Clin. Psychol. 79, 225-235 (2011).

8. Brown, S. L., Schwartz, G. E. \& Sweeney, D. R. Dissociation of self-reported and observed pleasure in depression. Psychosom. Med. 40, 536-548 (1978).

9. Negoias, S. et al. Reduced olfactory bulb volume and olfactory sensitivity in patients with acute major depression. Neuroscience 169, 415-421 (2010).

10. Fang, J., Demic, S. \& Cheng, S. The reduction of adult neurogenesis in depression impairs the retrieval of new as well as remote episodic memory. PLoS One 13, e0198406 (2018).

11. Barch, D. M. et al. Early childhood depression, emotion regulation, episodic memory, and hippocampal development. J. Abnorm. Psychol. 128, 81-95 (2019). 
12. Mathews, J. R. \& Barch, D. M. Episodic memory for emotional and nonemotional words in individuals with anhedonia. Psychiatry Res. 143, 121-133 (2006)

13. Bergouignan, L. et al. Field perspective deficit for positive memories characterizes autobiographical memory in euthymic depressed patients. Behav. Res. Ther. 46, 322-333 (2008).

14. Dillon, D. G. The neuroscience of positive memory deficits in depression Front. Psychol. 6, 1295 (2015).

15. Dillon, D. G. \& Pizzagalli, D. A. Mechanisms of memory disruption in depression. Trends Neurosci. 41, 137-149 (2018).

16. Koek, W., Sandoval, T. L. \& Daws, L. C. Effects of the antidepressants desipramine and fluvoxamine on latency to immobility and duration of immobility in the forced swim test in adult male C57BL/6J mice. Behav. Pharmacol. 29, 453-456 (2018).

17. Delgado, P. L. et al. Monoamines and the mechanism of antidepressant action: effects of catecholamine depletion on mood of patients treated with antidepressants. Psychopharmacol. Bull. 29, 389-396 (1993).

18. Dinan, T. G. Noradrenergic and serotonergic abnormalities in depression: stress-induced dysfunction? J. Clin. Psychiatry 4, 14-18 (1996).

19. Vadodaria, K. C. et al. Altered serotonergic circuitry in SSRI-resistant major depressive disorder patient-derived neurons. Mol. Psychiatry 24, 808-818 (2019).

20. Soblosky, J. S. \& Thurmond, J. B. Biochemical and behavioral correlates of chronic stress: effects of tricyclic antidepressants. Pharm. Biochem. Behav. 24 1361-1368 (1986).

21. Liu, Y., Zhao, J. \& Guo, W. Emotional roles of mono-aminergic neurotransmitters in major depressive disorder and anxiety disorders. Front. Psychol. 9, 2201 (2018)

22. Shelton, R. C. Serotonin and norepinephrine reuptake inhibitors. Handb. Exp. Pharmacol. 250, 145-180 (2016).

23. Liu, Z. W. et al. Postweaning isolation rearing alters the adult social, sexual preference and mating behaviors of male CD-1 mice. Front. Behav. Neurosci. 13, 21 (2019).

24. Boldrini, M. et al. Hippocampal granule neuron number and dentate gyrus volume in antidepressant-treated and untreated major depression. Neuropsychopharmacology 38, 1068-1077 (2013).

25. Joshi, S. H. et al. Structural plasticity of the hippocampus and amygdala induced by electroconvulsive therapy in major depression. Biol. Psychiatry $\mathbf{7 9}$ 282-292 (2016).

26. Santarelli, L. et al. Requirement of hippocampal neurogenesis for the behavioral effects of antidepressants. Science 301, 805-809 (2003).

27. Zhou, Q. G. et al. Regional-specific effect of fluoxetine on rapidly dividing progenitors along the dorsoventral axis of the hippocampus. Sci. Rep. $\mathbf{6}$ 35572 (2016)

28. Cacioppo, J. T. et al. Loneliness across phylogeny and a call for comparative studies and animal models. Perspect. Psychol. Sci. 10, 202-212 (2015).

29. Caruso, M. J. et al. Adolescent social stress increases anxiety-like behavior and alters synaptic transmission, without influencing nicotine responses, in a sexdependent manner. Neuroscience 373, 182-198 (2018).

30. Medendorp, W. E. et al. Altered behavior in mice socially isolated during adolescence corresponds with immature dendritic spine morphology and impaired plasticity in the prefrontal cortex. Front. Behav. Neurosci. 12, 87 (2018).

31. Nestler, E. J. \& Hyman, S. E. Animal models of neuropsychiatric disorders. Nat. Neurosci. 13, 1161-1169 (2010).

32. Amiri, S. et al. Co-occurrence of anxiety and depressive-like behaviors following adolescent social isolation in male mice; possible role of nitrergic system. Physiol. Behav. 145, 38-44 (2015).

33. Takatsu-Coleman, A. L. et al. Short-term social isolation induces depressive-like behaviour and reinstates the retrieval of an aversive task: mood-congruent memory in male mice? J. Psychiatry Neurosci. 38 259-268 (2013).

34. Leser, N. \& Wagner, S. The effects of acute social isolation on long-term social recognition memory. Neurobiol. Learn. Mem. 124, 97-103 (2015).

35. Kogan, J. H., Frankland, P. W. \& Silva, A. J. Long-term memory underlying hippocampus-dependent social recognition in mice. Hippocampus $\mathbf{1 0}$ 47-56 (2000).

36. Gusmão, I. D. et al. Odor-enriched environment rescues long-term social memory, but does not improve olfaction in social isolated adult mice. Behav. Brain Res. 228, 440-446 (2012).
37. Almeida-Santos, A. F. et al. Social isolation impairs the persistence of social recognition memory by disturbing the glutamatergic tonus and the olfactory bulb-dorsal hippocampus coupling. Sci. Rep. 9, 473 (2019).

38. Monteiro, B. M. et al. Enriched environment increases neurogenesis and improves social memory persistence in socially isolated adult mice. Hippocampus 24, 239-248 (2014)

39. Pereira-Caixeta, A. R. et al. Neurogenesis inhibition prevents enriched environment to prolong and strengthen social recognition memory, but not to increase BDNF expression. Mol. Neurobiol. 54, 3309-3316 (2017).

40. Pereira-Caixeta, A. R. et al. Inhibiting constitutive neurogenesis compromises long-term social recognition memory. Neurobiol. Learn. Mem. 155, 92-103 (2018).

41. Porsolt, R. D. Animal model of depression. Biomedicine 30, 139-140 (1979).

42. Costa, A. P. et al. A proposal for refining the forced swim test in Swiss mice. Prog. Neuropsychopharmacol. Biol. Psychiatry 45, 150-155 (2013).

43. Steru, L. et al. The tail suspension test: a new method for screening antidepressants in mice. Psychopharmacology (Berl.) 85, 367-370 (1985).

44. Pádua-Reis, M. et al. Reduced vesicular acetylcholine transporter favors antidepressant behaviors and modulates serotonin and dopamine in female mouse brain. Behav. Brain Res. 330, 127-132 (2017).

45. Sampson, D. et al. Decreased reactivity to sweetness following chronic exposure to mild unpredictable stress or acute administration of pimozide Neurosci. Biobehav. Rev. 16, 519-524 (1992).

46. Branchi, I., Alleva, E. \& Costa, L. G. Effects of perinatal exposure to a polybrominated diphenyl ether (PBDE 99) on mouse neurobehavioural development. Neurotoxicology 23, 375-384 (2002).

47. Bastos, C. P. et al. Object recognition memory deficit and depressive-like behavior caused by chronic ovariectomy can be transitorialy recovered by the acute activation of hippocampal estrogen receptors. Psychoneuroendocrinology 57, 14-25 (2015).

48. Bradford, M. M. A rapid and sensitive method for the quantitation of microgram quantities of protein utilizing the principle of protein-dye binding. Anal. Biochem. 72, 248-254 (1976)

49. Lookingland, K. J., Jarry, H. D. \& Moore, K. E. The metabolism of dopamine in the median eminence reflects the activity of tuberoinfundibular neurons. Brain Res. 419, 303-310 (1987).

50. Paxinos, G. \& Franklin, K. B. J. The Mouse Brain: In Stereotaxic Coordinates. 2nd edn. Academic, San Diego (2001).

51. Senst, L. et al. Sexually dimorphic neuronal responses to social isolation. Elife 11, 5 (2016).

52. Willner, P. Muscat, R. \& Papp, M. Chronic mild stress-induced anhedonia: a realistic animal model of depression. Neurosci. Biobehav. Rev. 16, 525-534 (1992).

53. Szczepanik, J. E. et al. Altered interaction with environmental reinforcers in major depressive disorder: relationship to anhedonia. Behav. Res. Ther. 97, 170-177 (2017).

54. Lumia, A. R. et al. Olfactory bulbectomy as a model for agitated hyposerotonergic depression. Brain Res. 587, 181-185 (1992).

55. Hellweg, R. et al. Olfactory bulbectomy in mice leads to increased BDNF levels and decreased serotonin turnover in depression-related brain areas. Neurobiol. Dis. 25, 1-7 (2007).

56. Magalhães, R. et al. A resting-state functional MR imaging and spectroscopy study of the dorsal hippocampus in the chronic unpredictable stress rat model. J. Neurosci. 25, 2192-18 (2019).

57. Sheline, Y. I., Liston, C. \& McEwen, B. S. Parsing the hippocampus in depression: chronic stress, hippocampal volume, and major depressive disorder. Biol. Psychiatry 85, 436-438 (2019).

58. Sun, $X$. et al. Fluoxetine enhanced neurogenesis is not translated to functional outcome in stroke rats. Neurosci. Lett. 603, 31-36 (2015).

59. Jayakumar, S. et al. Effect of fluoxetine on the hippocampus of Wistar albino rats in cold restraint stress model. J. Clin. Diagn. Res. 11, AF01-AF06 (2017).

60. Micheli, L. et al. Depression and adult neurogenesis: positive effects of the antidepressant fluoxetine and of physical exercise. Brain Res. Bull. 143 181-193 (2018).

61. Okuyama, T. et al. Ventral CA1 neurons store social memory. Science $\mathbf{3 5 3}$, 1536-1541 (2016).

62. Okuyama, T. Social memory engram in the hippocampus. Neurosci. Res. 129 17-23 (2018). 
63. Meira, T. et al. A hippocampal circuit linking dorsal CA2 to ventral CA1 critical for social memory dynamics. Nat. Commun. 9, 4163 (2018).

64. Chiang, M. C. et al. A role for CA3 in social recognition memory. Behav. Brain Res. 354, 22-30 (2018).

65. Papatheodoropoulos, C. \& Kostopoulos, G. Dorsal-ventral differentiation of short-term synaptic plasticity in rat CA1 hippocampal region. Neurosci. Lett. 286, 57-60 (2000).

66. Kheirbek, M. A. \& Hen, R. Dorsal vs ventral hippocampal neurogenesis: implications for cognition and mood. Neuropsychopharmacology 36 373-374 (2011).

67. Bagot, R. C. et al. Ventral hippocampal afferents to the nucleus accumbens regulate susceptibility to depression. Nat. Commun. 6, 7062 (2015).

68. Kaidanovich-Beilin, O. et al. Assessment of social interaction behaviors. J. Vis. Exp. 48, 2473 (2011).

69. Boero, G. et al. Impaired glucocorticoid-mediated HPA axis negative feedback induced by juvenile social isolation in male rats. Neuropharmacology 133, 242-253 (2018)

70. Yates, G. et al. Social isolation effects on the "behavioral despair" forced swimming test: effect of age and duration of testing. Physiol. Behav. 49 347-353 (1991).

71. Savignac, H. M., Dinan, T. G. \& Cryan, J. F. Resistance to early-life stress in mice: effects of genetic background and stress duration. Front. Behav. Neurosci. 5, 5-13 (2011)

72. Poulter, M. O., Du, L., Zhurov, V., Merali, Z. \& Anisman, H. Plasticity of the GABA (A) receptor subunit cassette in response to stressors in reactive versus resilient mice. Neuroscience 165, 1039-1051 (2010).

73. leraci, A., Mallei, A. \& Popoli, M. Social isolation stress induces anxiousdepressive-like behavior and alterations of neuroplasticity-related genes in adult male mice. Neural Plast. 2016, 6212983 (2016).

74. Sullivan, P. F., Kessler, R. C. \& Kendler, K. S. Latent class analysis of lifetime depressive symptoms in the national comorbidity survey. Am. J. Psychiatry 155, 1398-1406 (1998).

75. Li, Y. et al. The structure of the symptoms of major depression: exploratory and confirmatory factor analysis in depressed Han Chinese women. Psychol. Med. 44, 1391-1401 (2014).

76. Licinio, J. \& Wong, M. L. A novel conceptual framework for psychiatry: vertically and horizontally integrated approaches to redundancy and pleiotropism that co-exist with a classification of symptom clusters based on DSM-5. Mol. Psychiatry 18, 846-848 (2013).

77. Simmons, W. K. et al. Depression-related increases and decreases in appetite: dissociable patterns of aberrant activity in reward and interoceptive neurocircuitry. Am. J. Psychiatry 173, 418-428 (2016).

78. Wainwright, S. R. \& Galea, L. A. The neural plasticity theory of depression: assessing the roles of adult neurogenesis and PSA-NCAM within the hippocampus. Neural Plast. 2013, 805497 (2013).

79. Jacobs, B. L., van Praag, H. \& Gage, F. H. Adult brain neurogenesis and psychiatry: a novel theory of depression. Mol. Psychiatry 5, 262-269 (2000).

80. Strange, B. A. et al. Functional organization of the hippocampal longitudinal axis. Nat. Rev. Neurosci. 15, 655-669 (2014).

81. Fanselow, M. S. \& Dong, H. W. Are the dorsal and ventral hippocampus functionally distinct structures? Neuron 65, 7-19 (2010).
82. Gulyaeva, N. V. Functional neurochemistry of the ventral and dorsal hippocampus: stress, depression, dementia and remote hippocampal damage. Neurochem Res. 44, 1306-1322 (2018).

83. Feltmann, K. et al. Antidepressant drugs specifically inhibiting noradrenaline reuptake enhance recognition memory in rats. Behav. Neurosci. 129, 701-708 (2015).

84. Gonzáles, M. A. et al. Enduring attenuation of norepinephrine synaptic availability and augmentation of the pharmacological and behavioral effects of desipramine by repeated immobilization stress. Neuropharmacology 117, 249-259 (2017).

85. Lochmann, D. \& Richardson, T. Selective serotonin reuptake inhibitors. Handb. Exp. Pharmacol. 250, 135-144 (2019).

86. $\mathrm{Yu}, \mathrm{W}$. et al. Prenatal selective serotonin reuptake inhibitor (SSRI) exposure induces working memory and social recognition deficits by disrupting inhibitory synaptic networks in male mice. Mol. Brain 12, 29 (2019).

87. Siopi, E. et al. Anxiety- and depression-like states lead to pronounced olfactory deficits and impaired adult neurogenesis in mice. J. Neurosci. 36, 518-531 (2016).

88. Sun, Y. et al. Neuroplasticity and behavioral effects of fluoxetine after experimental stroke. Restor. Neurol. Neurosci. 35, 457-468 (2017).

89. Micheli, L. et al. Fluoxetine or Sox2 reactivate proliferation-defective stem and progenitor cells of the adult and aged dentate gyrus. Neuropharmacology 141, 316-330 (2018).

90. Alboni, S. et al. Hippocampus-related effects of fluoxetine treatment under stressful vs enriched conditions. Mol. Psychiatry 22, 483 (2017).

91. Conti, M. et al. Depressive-like phenotype induced by prenatal dexamethasone in mice is reversed by desipramine. Neuropharmacology 126, 242-249 (2017).

92. Dugué, G. P. \& Mainen, Z. F. How serotonin gates olfactory information flow. Nat. Neurosci. 12, 673-675 (2009).

93. Petzold, G. C., Hagiwara, A. \& Murthy, V. N. Serotonergic modulation of odor input to the mammalian olfactory bulb. Nat. Neurosci. 12, 784-791 (2009).

94. Kapoor, V. et al. Activation of raphe nuclei triggers rapid and distinct effects on parallel olfactory bulb output channels. Nat. Neurosci. 19, 271-282 (2016).

95. Martin, C., Beshel, J. \& Kay, L. M. An olfacto-hippocampal network is dynamically involved in odor-discrimination learning. J. Neurophysiol. 98, 2196-2205 (2007).

96. Aqrabawi, A. J. et al. Top-down modulation of olfactory-guided behaviours by the anterior olfactory nucleus pars medialis and ventral hippocampus. Nat. Commun. 7, 13721 (2016).

97. Kay, L. M. \& Laurent, G. Odor- and context-dependent modulation of mitral cell activity in behaving rats. Nat. Neurosci. 2, 1003-1009 (1999).

98. Mandairon, N. \& Linster, C. Odor perception and olfactory bulb plasticity in adult mammals. J. Neurophysiol. 101, 2204-2209 (2009).

99. Moreno, M. M. et al. Olfactory perceptual learning requires adult neurogenesis. Proc. Natl Acad. Sci. USA 106, 17980-17985 (2009).

100. Aqrabawi, A. J. \& Kim, J. C. Hippocampal projections to the anterior olfactory nucleus differentially convey spatiotemporal information during episodic odour memory. Nat. Commun. 9, 2735 (2018). 